\title{
O Jornal Amapá e a literatura amapaense: os anos entre 1945 e 1968
}

Yurgel Pantoja Caldas ${ }^{1}$

http://lattes.cnpq.br/7404598847087083

Manoel Azevedo de Souza ${ }^{2}$

Enviado em: 04/09/2017

Aceito em: 08/03/2018

Resumo: Este trabalho constitui um estudo sobre a importância do jornalismo na divulgação de obras e escritores amapaenses ou radicados no Amapá, através de diversos textos publicadas no Jornal Amapá, durante o período de sua publicação: 1945-1968. Os textos selecionados do referido jornal são documentos de uma época e se configuram como lugares de memória escrita, que permitem o conhecimento da formação histórica e identitária do Amapá, a partir de sua literatura. Com a transformação em território federal (1943), o Amapá reconfigurava seu espaço no cenário político, social e econômico da Amazônia, daí inúmeras referências sobre ocupação e desenvolvimento apresentadas pelo Jornal Amapá. De modo geral, essas referências oferecem um painel sobre a construção das identidades amapaenses pela literatura produzida naquele espaço.

Palavras-chave: Jornal Amapá; Literatura Amapaense; Identidade.

Abstract: This work constitutes a study about the importance of journalism in the dissemination of works and writers in Amapá, through several texts published in the Jornal Amapa, during the period of its publication: 1945-1968. The selected texts of this newspaper are documents of a time and are configured as places of written memory, which allow the knowledge of the historical and identity formation of Amapá, from its literature. With the transformation into federal territory (1943), the Amapá reconfigured its space in the political, social and economic scenario of the Amazon, hence numerous references on occupation and development presented by the Jornal Amapá. In general, these references offer a panel on the construction of the identities of Amapá by the literature produced in that space.

Key-words: Jornal Amapá; Literature of Amapá; Identity.

\section{Introdução: o Jornal Amapá no contexto do Território Federal}

O acervo do Jornal Amapá está guardado na seção de obras raras da Biblioteca Pública Elcy Lacerda, localizada no centro da cidade de Macapá, capital do Estado do Amapá. Nesse contexto, é importante considerar que o

discurso jornalístico toma parte no processo histórico de seleção dos acontecimentos que serão recordados no futuro. E mais ainda: uma vez que ao selecionar está engendrando e fixando sentido para estes acontecimentos, a impressa acaba por constituir no discurso um modo (possível) de recordação do passado (ORLANDI, 1993, p. 33).

\footnotetext{
${ }^{1}$ Professor do Departamento de Letras e Artes da UNIFAP e do Programa de Pós-graduação/Mestrado em Desenvolvimento Regional, da mesma instituição.

2 Professor do Departamento de Letras e Artes da UNIFAP, Doutor em Sociologia.
} 
O jornal enquanto fonte e documento de reconstituição histórica funciona, assim, como suporte da memória. Sobre essa questão, Vesentini (1997, p. 37) apresenta uma interessante reflexão para o pesquisador quanto ao uso do jornal como objeto de estudo:

Eles podem ser bem mais, muito mais que folhas mortas, de um tempo igualmente morto, à espera do meu labor, por exemplo. Eles são dotados de ação. Quero dizer que muitas dessas páginas amadas por nós e prediletas na ação do exame, não são textos nada neutros [...] eles expressão práticas políticas, de lutas políticas, sendo, naquele momento, consubstanciação dessa mesma prática, práxis, de sujeitos concretos.

O Jornal Amapá foi o periódico amapaense que atingiu a mais longa duração na fase de território federal (1943-1988). Foram 1479 edições entre os anos de 1945 a 1968. Mesmo considerando que, de modo geral, o Jornal Amapá pouco contribuía para uma visão crítica da realidade - visto que predominava o texto informativo, o opinativo e o de entretenimento -, há de se reconhecer que, do ponto de vista da informação, ele foi responsável por uma maior divulgação do Amapá tanto no cenário regional quanto no nacional.

Dessa maneira, a análise do Jornal Amapá é particularmente relevante por retratar nas imagens e nos seus discursos as histórias que contam versões dos fatos trazendo à tona, pelo recurso da memória, temas importantes (como o político-social) para uma discussão mais ampla da sociedade e posicionando o jornal em relação ao que acontece na cidade, na região e no país.

Do ponto de vista da linguagem jornalística do período territorial, pode-se dizer que os discursos sobre o Amapá caracterizam-se por apresentar uma linguagem regional, com base em "um discurso performativo que pretende fazer sobrevir o que ele enuncia no próprio ato de enunciar [que] é proporcional à autoridade daquele que o enuncia" (BOURDIEU, 2006, p. 116). Assim, os discursos sobre o Amapá destacam, nas páginas do Jornal Amapá, a busca por uma legitimidade de determinado olhar com seus desdobramentos os quais dão a conhecer uma região que vivenciou um processo histórico que lhe é próprio.

Esses discursos regionalistas inscrevem o Amapá na construção de sua própria memória. Assim sendo, essa produção textual, tomada como representação sobre o espaço amapaense, compõe um conjunto de textos que podem ser culturalmente interpretados. Essa afirmativa é válida e representa uma escolha que demanda um esforço interpretativo de contextualização histórica, cultural e social dessa produção rememorada.

\section{A cidade de Macapá como epicentro da Mística do Amapá ${ }^{3}$}

Em 13 de setembro de 1943, pelo Decreto-Lei 5.812, o Amapá é desmembrado do Estado do Pará com a criação do Território Federal ${ }^{4}$. O Amapá está situado na parte

\footnotetext{
3 “A mística do Amapá é o ideal de torná-lo uma das regiões nacionais mais ricas e felizes do Brasil. Ela não tem dono nem autor. Não pertence a um grupo, a uma seita a um partido. Existe na alma do povo, palpita no coração de todos os que crêm na beleza de seu futuro. Como nasceu essa mística? Fruto do amor, através da história, do guales que se apaixonaram pela terra. Cada sonho, cada esperança, cada luta, vividos para torná-la mais próspera, emprestaram-lhe fôrça e brilho. Ela resume os anseios mais nobres de quantas batalharam para integrar o Amapá na Pátria Brasileira. Durante séculos seu tempo foi a natureza virgem. Acompanhou os pioneiros que penetraram a gleba em busca de riquezas e os viajares curiosos por devassarem um mundo novo. E realizou o milagre de apagar a ânsia de gozar noutras plagas os frutos conseguidos, fazendo-os edificarem aí seus lares definitivos, empregando-lhes o íntimo de profundo e inextinguível simpatia pelas paisagens e coisas locais" (JORNAL AMAPÁ, 17 de maio de 1952).

${ }^{4}$ De 1944 até 1990, o Território Federal do Amapá teve seus governadores (na maioria militares de outros Estados)
} 
setentrional do Brasil, quase inteiramente incluído no hemisfério norte onde a linha imaginária do equador (que divide o globo terrestre em dois hemisférios, norte e sul) passa ao sul da cidade de Macapá, a capital do Amapá. As fronteiras do Amapá são: ao norte com a Guiana Francesa, ao leste com o Oceano Atlântico, a noroeste com o Suriname e a oeste e sul com o estado do Pará. O rio Amazonas, o mais volumoso do mundo, banha Macapá, sendo a única capital brasileira nessas condições. O clima no Amapá é predominantemente equatorial (quente e úmido); sua vegetação é coberta pela típica floresta equatorial, sendo considerado ainda hoje, conforme o Instituto Brasileiro de Meio Ambiente - IBAMA (2014), o Estado brasileiro mais preservado ambientalmente.

Como já referido anteriormente, o Território Federal do Amapá foi criado dentro de uma conjuntura que apresentava um acentuado sentimento nacionalista - fruto principalmente de sua "independência" econômica e da busca de uma integração nacional de áreas distantes dos centros econômicos e de difícil acesso, especialmente na Amazônia.

Esse nacionalismo repercutiu também na imprensa. No caso específico do Amapá, a partir de 1945, o jornal impresso firmou-se como o principal meio de comunicação de massa - aspecto que não passou desapercebido aos governantes, que o utilizavam para veicular discursos, mensagens e notícias oficiais como instrumentos de propaganda das gestões político-administrativas.

Nesse contexto, o Jornal Amapá, durante o período de sua circulação, funcionou também como uma espécie de porta-voz do Governo do Amapá. Em sua linha editorial, proclama incessantemente o ideal de um Amapá que na longínqua Amazônia se preparava para ser "grandioso". Desse modo, passam a surgir os primeiros discursos que se revelam como uma estratégia política para a construção das identidades amapaenses ${ }^{5}$.

\section{A imprensa no Amapá}

A história da imprensa na Amazônia, assim como em grande parte do Brasil, é marcada inicialmente pela ampla divulgação das atividades políticas do Brasil imperial e, particularmente, pelo (re)conhecimento e divulgação da própria região amazônica em escala nacional.

A editoração dos primeiros jornais na Amazônia contou com tecnologia importada da Europa, cuja condição para sua chegada deu-se principalmente pela inserção da região no mercado econômico internacional, em função do ciclo da borracha na região (segunda metade do século XIX e início do século XX), com a oferta do produto especialmente para os países da Europa. Nesse contexto, as duas maiores cidades da região, Belém e Manaus, incorporavam-se na era da modernidade, a partir do modelo de urbanização europeia, vivenciando a chamada Belle Époque que tem como referencia a modo de vida glamuroso da sociedade burguesa europeia, sobretudo parisiense.

No Amapá, o cenário no qual a atividade de imprensa foi criada se aproxima muito de

nomeados pelo poder da União. Nesse intervalo de 46 anos passaram pela cadeira do executivo amapaense 16 governadores, como podemos ver no quadro a seguir. Os governadores militares ficavam por mais tempo, em média 04 anos, enquanto os não militares a média era de um ano, provavelmente só enquanto aguardavam a nomeação pela presidência da república, de um governador militar.

${ }^{5}$ Escolhemos textos representativos de três décadas diferentes, como segue: "A obra dos homens que aqui trabalham é bem uma continuação do esforço heroico dos primeiros colonizadores", de Sílvio Meira, Deputado Estadual pelo Pará (Jornal Amapá, 15 de setembro de 1949); "Em Macapá”, de Mennotti Del Picchia, poeta e político (Jornal Amapá, 18 de outubro de1952) e "Viagem à Amazônia", de Raquel de Queiroz, ficcionista (Jornal Amapá, 22 de maio de 1965). 
como funcionou os primeiros serviços tipográficos em outros espaços da Amazônia e, de certo modo, das condições em que também funcionou inicialmente a imprensa nacional, especialmente no que diz respeito aos homens mais "letrados", a quem lhes foram dadas prerrogativas de tradutores, intérpretes e porta-vozes das ideias daqueles que estavam no poder. Nesse sentido, Morel (2015, p. 104) afirma que a

imprensa constituiu-se como formuladora de projetos de nação distintos entre si (apesar das convergências) e de uma cena pública cada vez mais complexa, na qual emergiam atores políticos diferenciados. Permeiam as páginas dos jornais como protagonistas: soldados, oficiais de média patente, lavradores arrendatários, profissionais liberais, clero regular e secular, camadas pobres urbanas livres, homens negros, pardos e brancos, além da presença nítida das mulheres na cena pública, como leitoras ativas.

As atividades tipográficas e a veiculação de jornais no Amapá são anteriores a seu desmembramento do Estado do Pará, com a criação do Território Federal, em 1943. O primeiro jornal a circular no Amapá foi o Pinsonia ${ }^{6}$, ainda em 1895, por iniciativa de Joaquim Francisco de Mendonça Junior e de José Antonio de Siqueira.

O Pinsonia era impresso no formato tabloide, com circulação semanal. Ressalte-se que suas primeiras edições não foram feitas no Amapá, mas em Belém. Em 1897, chegam a Macapá máquinas alemãs para a impressão do referido jornal, que dois anos depois pararia de circular.

Durante o período de sua circulação, o Pinsonia evidenciou a própria região amazônica e as questões relacionadas à cidade de Macapá. Desse modo, os textos de cunho regional e local vão aos poucos ocupando espaço naquele jornal e os assuntos de natureza endógena tornam-se mais relevantes.

O Jornal Amapá, por sua vez, começou a circular em 19 de março de 1945, com um lançamento festivo, que coincidiu com o dia nacional da imprensa oficial e o dia do santo padroeiro da cidade de Macapá, São José. Tal publicação constituiu-se basicamente como um informativo do governo do Território Federal do Amapá, após a sua criação em 1943, mas também servia para divulgar notícias do cotidiano amapaense, com maior destaque para a capital, Macapá.

O Jornal Amapá foi, durante o período de 1945 a 1968, a principal mídia impressa do Amapá, contando com uma ampla circulação. Apesar de ser também um informativo do Território Federal do Amapá, e que de muitas formas refletia a orientação política do governo, o referido jornal pode ser caracterizado como um periódico de temática livre, com assuntos diversificados, apresentando conteúdos informativos, notícias, opiniões e análises, anúncios e propagandas.

Desde o primeiro número e na sua primeira página, o Jornal Amapá já se anunciava como um mecanismo não apenas de difusão dos programas do primeiro governo do recémcriado Território Federal do Amapá, mas também como um espaço de divulgação e afirmação das identidades amapaenses. Pode-se dizer que o Jornal Amapá foi um periódico feito pelo governo do Território Federal do Amapá voltado primeiramente para atender aos seus interesses. Basta observarmos, por exemplo, que era comum em quase todas as edições, discursos elogiosos ao Amapá feitos por figuras públicas, especialmente políticos, militares e jornalistas que visitam pela primeira vez o Território Federal do Amapá.

Assim, é interessante verificar que, se por um lado o Jornal Amapá enfatizava mais as

${ }^{6} \mathrm{O}$ nome do periódico está relacionado a uma homenagem prestada ao navegador espanhol Vicente Yánes Pinzón, descobridor da foz do Rio Amazonas, em 1500.

https://periodicos.unifap.br/index.php/letras

Macapá, v. 8, n. 3, $2^{\circ}$ sem., 2018 
notícias sobre a "prosperidade" que vinha acontecendo no novo território federal, por outro, tornou-se o veículo de comunicação mais eficiente da época, que aos poucos foi ganhando maior penetração na comunidade amapaense, principalmente quando aumentou o número de alfabetizados - condição em que o jornal passa a ser mais lido (consumido).

\title{
Literatura e memória: interseções com o cotidiano macapaense
}

O Jornal Amapá passou a veicular, a partir das edições do ano 1950, uma seção cultural onde divulgava as produções literárias amapaenses por iniciativa dos recém-chegados escritores que vieram prestar serviços como servidores públicos no Território Federal do Amapá. Trata-se de uma das seções mais regulares do jornal, considerada de vanguarda na divulgação das primeiras expressões literárias amapaenses, visto que, na época, era o principal e mais eficiente meio de divulgação da produção daqueles escritores. A seção normalmente se localizava na terceira página do jornal.

As características do Amapá, o ufanismo, a memória e o cotidiano da cidade de Macapá são temas recorrentes nos textos literários publicados no Jornal Amapá dos quais selecionamos alguns que serão abordados a seguir, começando pelo icônico poema "Macapá" (publicado pela primeira vez na Revista de Educação e Ensino do Pará, em 1889 e republicado no Jornal Amapá, em 20 de março de 1948), de Alexandre Vaz Tavares?

O citado poema nos mostra como principal temática a descrição das lembranças da cidade de Macapá, e revela um cenário que confronta o passado com uma inércia ao desenvolvimento e o presente, configurando uma cidade que crescia dia a dia, com a festejada presença do "progresso". Destaquem-se, anterior ao período territorial, as lembranças do autor, que percorrem cenários com fortes relações afetivas, como na passagem a seguir:

\author{
Trajava a cidade inteira \\ Alva roupagem faceira \\ Pela data brasileira \\ Ou festa de devoção \\ Então que alegre não era \\ Ver-se o ledo rodopio \\ Em manhãs de primavera \\ Ou nas tardinhas do estio \\ De um povo em festa a folgar: \\ Moças com laços de cores \\ Raparigas com mil flores \\ Rapazes buscando amores... \\ Tudo era rir e brincar!
}

Ainda a esse respeito, como se dialogasse com o poema de Vaz Tavares, Aracy Mont'Alverne ${ }^{8}$ escreveu o poema "Macapá Cinderela" seguindo o rastro memorialista de

\footnotetext{
${ }^{7}$ Amapaense nascido em 1858, formado em Medicina pela Faculdade do Rio de Janeiro. Juntamente com as atividades profissionais desenvolvidas em Macapá e Belém, também percorreu os caminhos das Letras sendo considerado o precursor da literatura amapaense. No seu poema "Macapá", o autor registra a cidade iniciando uma fase de crescimento urbano, no contexto do elogio do período republicano em detrimento da monarquia, a quem o poeta atribui a maldição do atraso da cidade de Macapá. Vaz Tavares morreu em Macapá, em 1926.

8 Professora e escritora nascida em 1913, na cidade de Colares, no Pará. Chegou ao Amapá em 1942 e exerceu suas atividades principalmente na educação, sendo a primeira mulher secretária de educação do Território Federal do
} 


\section{Vaz Tavares:}

65

Macapá Cinderela

Macapá já foi outrora

Uma menina do mato...

Tão pequenina e franzina,

Doentia, retraída,

E que vivia esquecida...

$[\ldots]$

Hoje a menina está moça,

E ainda está crescendo,

Já é por todos notada

Está se desenvolvendo,

E quando ouve dizer

Com admiração,

Que é São Paulo ou Brasília,

Do Brasil o coração

Ela toda ufana diz:

"Eu também sou importante,

Sou a cabeça do País"

$[\ldots]$

Cresceu muito, ficou forte,

É a Cinderela do Norte!

Tem saúde, tem escolas

Para se aperfeiçoar.

Tem ouro e joias bonitas...

Até não usa mais chita!

Vem gente lá de outras terras,

Aos grupos lhe visitar

É gentil, não é orgulhosa,

A todos sabe tratar.

(in JORNAL AMAPÁ, 20 de setembro de 1956)

Pelas memórias da autora, vê-se Macapá como uma "menina” interiorana que, com o passar do tempo, está se desenvolvendo. Esse crescimento é traduzido pela imagem de novas ruas, casas em alvenaria, praças, escolas, hospital e o crescimento populacional sinais claros da modernização, movimento inevitável da urbanização de uma cidade.

Outro texto, desta feita na forma da prosa de Isnard Lima ${ }^{9}$, vai na mesma direção memorialista da poesia de Mont'Alverne:

\section{O "Bandeirante" Janary Nunes}

Faz anos, em 42, quando o "Senhor Destino" me atirou às terras do Amapá não esperava eu retornar neste hoje para revê-las cobertas de flores, tendo a engrinaldá-las esta Meca onde não estrugem lamentações, mas os mandamentos do trabalho. Macapá, vi-a em pequenina... Novo Presépio a crescer na amplitude deste Amazonas que aprendi a amar e percorrer seu imenso estuário, ao fascinar-me à luz violeta de seus lagos, no rugir da pororoca à magia dos silfos e boiunas [...]. No extremo do Brasil meus olhos não encontram aproveitamento de riqueza talqualmente o que vejo aqui, neste começo do abraço fraterno em que o Rio-Mar se irmana ao

Amapá. Como poeta, deixou várias obras literárias, inclusive algumas ainda inéditas. Morreu em Macapá, no ano de 2002.

9 Isnard Brandão de Lima Filho nasceu em Manaus (1941) e veio definitivamente para o Amapá em 1949. Poeta e advogado, dedicou a maior parte de sua vida à literatura. Morreu em 2002, em Macapá. 
oceano tenebroso! Palmo a palmo perlustrei o território nacional e, mais incansavelmente, talvez, esta maior partícula da Pátria. Entretanto, ali ou acolá, nunca jamais presenciei tão rápido subir duma comunidade do que em Macapá (JORNAL AMAPÁ, 5 de abril de 1952).

A crônica apresenta, pelas memórias do autor, o espaço amapaense em suas peculiaridades naturais abundantes, cujas formas exóticas compõem a natureza em todo seu esplendor, desde o silêncio das matas ao "rugir" da pororoca, passando pela magia da boiuna, fazendo com que o encanto dessa natureza desperte o orgulho pela região. Esse sentimento ufanista, sempre ele, transmite a percepção de duas realidades: uma tradicional, que expressa um conjunto de valores culturais coletivos relativos ao meio ambiente que, mesmo diante das mudanças do mundo moderno, a comunidade procura resguardar esses valores adquiridos ao longo do tempo, visto que

Nas culturas tradicionais, o passado é honrado e os símbolos valorizados porque contêm e perpetuam a experiência de gerações. A tradição é um modo de integrar a monitoração da ação com a organização tempo-espacial da comunidade. Ela é uma maneira de lidar com o tempo e o espaço, que insere qualquer atividade ou experiência particular dentro da continuidade do passado, presente e futuro, sendo estes por sua vez estruturados por práticas sociais recorrentes (GIDDENS, 1991, p. 38).

A outra realidade apresentada é a visão do autor como um flâneur diante de uma cidade cuja transformação paisagística foi tão rápida. Assim, passam pelos olhos novas imagens que se tornarão suportes para novas memórias (sempre em movimento): "Entretanto, ali ou acolá, nunca jamais presenciei tão rápido subir duma comunidade do que em Macapá”. Nesse processo, é a dimensão do espaço/lugar que torna possível a consolidação e a estabilidade da memória, pois as imagens construídas no processo de memorização estão vinculadas ao espaço. A memória do autor, portanto, conforme Delgado (2010, p. 62), "traduz registros de espaços, tempos, experiências, imagens e representações" da cidade que ele vê e que por ela é visto.

Portanto, tomando emprestada a formulação sistemática do poema épico - donde se tem um jogo que ressalta o heroísmo de um povo em detrimento de suas fraquezas, que não podem ser mencionadas no texto narrativo-laudatório - a relação estabelecida entre a literatura e a memória é possibilitada pelo jogo de lembrança e esquecimento, através do qual os aspectos positivos de certa comunidade devem ser exaltados e sempre lembrados, enquanto as falhas e desacertos nunca são mencionados num texto que se quer memorial e definitivo. Tal movimento tem a ver com "reencontrar temporalidades [...] lugares e identidades" (DELGADO, 2010, p. 120).

Os escritores amapaenses destacados trazem em suas memórias um reconhecimento do presente e a valorização do passado. Enxergam na cidade de Macapá dos "bons tempos" (o passado) com especificidades que tornam aquele espaço particular, mas que se constituem coletivos pela socialização de suas obras literárias e pelos sentimentos de identificação que são criados e reforçados com tais obras.

Conforme Delgado (2010), história, tempo e memória são processos interligados. No entanto, o tempo da memória vai além do tempo de vida individual e encontra-se com o tempo da história, visto que ele (o tempo) se alimenta de lembranças. Dessa forma, Arthur Nery Marinho ${ }^{10}$ busca poetizar a cidade, através da sua praça mais antiga como um flanêur,

${ }^{10}$ Natural de Chaves, no Pará (1923), Nery Marinho chegou a Macapá em 1945, como funcionário do território federal.
Foi diretor da Imprensa Oficial entre os anos de 1955 e 1962, Chefe de Gabinete do Governador em 1963. Morreu

https://periodicos.unifap.br/index.php/letras Macapá, v. 8, n. 3, $2^{\circ}$ sem., 2018 
na tentativa de retomar o passado pela crítica à modernidade que obstrui a antiga paisagem macapaense. O poeta também critica a ânsia por uma cidade moderna sem a preocupação com os valores existentes na paisagem já construída e permanente no tempo e no espaço:

\section{Praça Antiga}

Velha praça, velha praça,

Tenho saudade de ti.

Não da bonita que está

Mas da que eu conheci:

A praça do Tio Joãozinho

E do seu Naftali.

O primeiro era Picanço

E o segundo Bemergui.

A praça do João Artur,

Também a praça do Abraão

A praça que foi outrora

Da cidade o coração.

A praça que se jogava

Todo dia o futebol,

Esporte que só findava

quando já dormia o sol.

Parece que isto foi ontem,

Mas tanto tempo passou.

O que deixou de existir,

Minha saudade gravou.

Vejo a barraca da Santa,

Vejo ali o ABC.

há muito já não existem,

Mas a minha saudade os vê.

Da igreja o velho coreto

Eu avisto, neste ensejo.

Do Mestre Oscar vejo a Banda.

E lá na banda eu me vejo.

Eu considero um castigo!

Não apagar da lembrança!

$\mathrm{O}$ que me foi alegria

E agora é desesperança.

Velha praça, velha praça,

Renovastes e linda estás.

Não tens, porém, a poesia

Do que ficou para trás.

(in JORNAL AMAPA, 13 de setembro de 1954).

A visão desse espaço oscila entre o saudosismo memorialista, o resgate das tradições e a visão ufanista do autor, todos convergindo para a ênfase nos lugares de memória e nas personagens históricas. Segundo Nora (1993, p. 9), "a memória é a vida, sempre carregada por grupos vivos e, nesse sentido, ela está em permanente evolução, aberta à dialética da lembrança e do esquecimento".

Aquela praça do poema de Marinho representava o "coração", a essência da cidade de

em Macapá no ano de 2003.

https://periodicos.unifap.br/index.php/letras

Macapá, v. 8, n. 3, $2^{\circ}$ sem., 2018 
Macapá - local que simbolizava, do ponto de vista coletivo, um bem afetivo indispensável à comunidade. Nas lembranças do texto, descrevem-se os cenários preservados pela memória, ora apresentando a inexorável dinâmica do crescimento urbano de Macapá:

\footnotetext{
Velha praça, velha praça,

Tenho saudade de ti.

Não da bonita que está

Mas da que eu conheci $[. .$.

Parece que isto foi ontem,

Mas tanto tempo passou.

O que deixou de existir,

Minha saudade gravou;
}

ora ressaltando que esses espaços íntimos estão recobertos de importantes significações simbólicas, ou seja, fazem parte de um cenário que, suscitado metaforicamente, remete ao seu mundo interior habitado por reminiscências: a praça e a comunidade que, com o passar do tempo, vão se modificando:
Velha praça, velha praça,
Renovastes e linda estás.
Não tens, porém, a poesia
Do que ficou para trás.

Desse modo, ao descrever e nomear cuidadosamente a primeira praça de Macapá, é como se o poeta cidadão (aquele que conhece e percorre as trilhas da sua cidade, pois se apropria desse espaço criativo) estivesse palmilhando-a e nela encontrando suas raízes, sua identidade, pelo recurso da memória, pois o

relembrar é uma atividade mental que não exercitamos com frequência porque é desgastante ou embaraçosa. Mas é uma atividade salutar. $\mathrm{Na}$ rememoração reencontramos a nós mesmos e a nossa identidade, não obstante muitos anos transcorridos, os mil fatos vividos [...]. Se o futuro se abre para a imaginação, mas não nos pertence mais, o mundo passado é aquele no qual, recorremos a nossas lembranças, podemos buscar refúgio dentro de nós mesmos, debruçarnos sobre nós mesmos e nele reconstruir nossa identidade (BOBBIO, 1997, p. 30-31).

Nesse contexto, a Fortaleza de São José de Macapá, que está entre os cartões-postais mais significativos da memória da cidade, pode ser considerada uma espécie de imagem que sintetiza Macapá, ou seja, um espaço simbólico edificado para impedir a entrada, pelo rio Amazonas, de nações estrangeiras. Veja-se o discurso sobre esse monumento:

Sentinela do Brasil na entrada do rio-mar, a Fortaleza de São José de Macapá, situada à margem do braço norte do Amazonas, na capital do Território Federal do Amapá, apresenta ao visitante um espetáculo que na verdade empolga. Trata-se de um monumento histórico de incalculável significação nacional, que encanta aos visitantes, pelo cuidado com que está sendo conservado e pela riqueza de patrimônio histórico que nela acumula (in JORNAL AMAP $A, 7$ de fevereiro de 1954).

A memória encontra aqui, na coisa em si concreta, a chave para aqueles que "vêm após os que construíram o monumento. No monumento como signo que tenta vincular passado e futuro. No monumento, ou na lápide, que se supõe avisará aos que vêm depois o que foi 
que aconteceu antes" (ACHUGAR, 2006, p. 172). Essa questão é retomada no poema a seguir, de Carlos Cordeiro Gomes:

O Forte de São José de Macapá

Monumento histórico,

Paredão inflexível.

Enciclopédia que guarda os acontecimentos de uma época.

Nas minhas sucessivas noites de insônia, revivo fatos que a história jamais publicou.

Um grupo de lusitanos

cantando canções de Portugal.

A sentinela, na sua ronda habitual, e o eco dos seus passos comedidos inquietava a população da vila de São José de Macapá.

$\mathrm{Na}$ guarita, o português sonhava

com uma "cachoupa" de longas tranças e saia de xadrez

Discernia poeticamente das coisas e os mistérios da vila.

As noites eram noites negras...

Os canhões enlutados cuspiam fogo

na primeira veleira que transpusesse a demarcação...

As garças que pescavam nas margens do rio, fugiam, assustadas.

Na galé,

os gemidos dos prisioneiros uniam-se aos cânticos agourento das aves noturnas

Não havia clemência!

Todos pagavam com a vida tamanha ousadia...

Hoje, essa herança portuguesa, reflete, no seio de uma cidade moderna,

os acontecimentos históricos da vila de São José de Macapá.

(in Jornal Amapá, 24 de março de 1954).

77 "Cidade joia da Amazônia” foi uma expressão muita utilizada pela população amapaense para se referir a cidade de Macapá principalmente nos anos de 1960-1970, por esta apresentar, nesse período, um amplo desenvolvimento urbano, destacando-se o traçado das ruas retas e largas e bastante arborização na maioria dos bairros.

Por fim, é preciso lançar um olhar sobre a Belle Epoque em Macapá, retomando os percursos da memória histórica, da memória coletiva e do próprio discurso da história. Nessa direção, o Jornal Amapá é um importante instrumento para a memória daquele período, principalmente pelos caminhos da crônica e dos registros que sociabilizam a experiência urbana. Nas páginas do referido jornal, já com grande circulação na capital no início dos anos 1950, é possível flagrar os discursos da "modernidade", do desenvolvimento urbano, da "belle époque" que chegava ao Território Federal do Amapá, mais especificamente em Macapá, que vivia um processo de urbanização proporcionado principalmente pelo crescimento dos setores públicos (funcionalismo) e privados (empresas ligadas à exploração do manganês).

Em 1953, o Jornal Amapá, em seu editorial, publicava uma crônica denominada de "Macapá Moderna", ressaltando seu desenvolvimento urbanístico. No texto, há uma comparação entre a cidade de poucas décadas atrás com a "nova" Macapá que então emergia: se a de ontem era "recatada", muita pequena e atrasada, uma "cidadezinha qualquer" (para falar como Drummond, o poeta da pequena e pacata Itabira mineira), a atual mais parecia uma "fênix" renascida, cheia de mocidade e encantos, pois agora era

Uma cidade traçada geometricamente, com ruas e avenidas largas, mostrando fisionomia agradável e moderna. Possuindo rede de esgotos, água encanada, energia elétrica permanente, piscina, ótimo hotel, cinema, bares, cafés, frigorífico, lojas, farmácias, armazéns etc., proporciona 
aos visitantes e moradores conforto, prazer e tranquilidade. Nada menos que seis aviões semanais pousam em seu aeroporto, sempre lotados de passageiros e carga. Como sala de visita do Território, Macapá está sendo preparada sob a técnica e figurino modernos. [...]. Vivemos todos estreitamente vinculados à própria alegria que dá novo colorido a esta Macapá que, como mulheres bonitas, também mostra sua vaidade frente do toucador onde realça a sua fisionomia simpática e a sua mocidade atraente (in JORNAL AMAPÁ, 13 de setembro de 1953).

Deslumbrado com aquelas coisas novas que em tão pouco tempo modificavam o perfil da capital, o artigo do jornal concluía que, de fato, a "civilização" chegara a Macapá: "Tudo aqui dentro empolga a alma do povo e surpreende o visitante [...] já aparecendo aos olhos da atualidade como uma cidade nortista onde se instalou a civilização" (in JORNAL AMAPA, 13 de setembro de 1953).

A crônica, desta forma, resume parte do conjunto de novos costumes e equipamentos tecnológicos que formaram o processo de modificação social e urbana de Macapá, iniciado a partir de 1950, indo até o final dos anos de 1960. Esse processo significou a inserção da capital amapaense no contexto de uma Belle Epoque, mesmo que tardia em relação a outras capitais brasileiras.

A introdução de um grande número de automóveis em Macapá, a partir dos anos de 1950, imprimiu nova dinâmica ao trânsito da cidade, provocando muitos atropelamentos. Nesse caso, foi necessária a abertura de novas ruas e avenidas; uma maior extensão de calçamentos/calçadas; a criação da guarda de trânsito; a introdução de semáforos e a reorientação de pedestres e ciclistas (em expressivos números na época) para um novo uso do espaço urbano.

O boom desse desenvolvimento também possibilitou que viessem a Macapá importantes companhias teatrais e musicais. O Jornal Amapá na época comentava o desempenho dos artistas, a presença de autoridades e intelectuais em tais eventos. Para melhor fomentar essas atividades artísticas, é criada em 1951 a Sociedade Artística de Macapá (SAM), que tinha como uma de suas principais finalidades "patrocinar a vinda a este recanto verde do Brasil, de todos os expoentes das artes, principalmente no que diz respeito à música e ao canto, as que são evidentemente mais sensíveis ao povo" (in JORNAL AMAPA, 13 de setembro de 1951).

Contudo, para imprimir definitivamente a dinâmica da "modernidade" em Macapá, o poder público implementou uma "disciplinarização" do espaço urbano, regulando o cotidiano da cidade, que se tornou atribulado em função da intensificação do seu próprio fluxo, desencadeado pelo crescimento populacional (no ano de 1960 o número de habitantes de Macapá atinge aproximadamente $30 \mathrm{mil}^{11}$ ), pelo aumento na frota de automóveis e de estabelecimentos comercias no perímetro central da cidade.

Em razão desse volume crescente, os conflitos foram inevitáveis, principalmente porque o poder público também se manifestava num sutil combate aos grupos populares (especialmente negros) e de baixa renda do centro da cidade, forçando-os a procurar os subúrbios da capital, como aconteceu com os negros que residiam em áreas na frente da cidade e foram desapropriados de suas casas para os bairros do Laguinho e da Favela (atual Santa Rita). Daí a composição de uma canção de Marabaixo, composta por um desses moradores, Raimundo Ladislau, revelando sua tristeza pela desapropriação daquelas casas populares que deram lugar à construção de modernas moradias para o alto escalão da administração territorial ${ }^{12}$.

\footnotetext{
${ }^{11}$ Dados do VII Censo Nacional no ano de 1960, publicado no Jornal Amapá, em 9 de outubro de 1960.

12 "Aonde tu vai, rapaz?/ Por esses caminhos, sozinho?/ Vou fazer minha morada/ Lá nos campos do Laguinho."
} 
Com essa nova configuração, o centro da cidade de Macapá já não seria o mesmo. A tranquilidade, a vivência sem pressa, que contagiava as pessoas cedeu lugar às inexoráveis mudanças inerentes à modernidade do cenário urbano. Assim sendo, não há como negar que o Amapá, mesmo que com algum atraso, também conheceu a sua Belle Epoque, aqui entendida como manifestação e representação de padrões da cultura burguesa que se espalhou de forma mais ampla no Brasil, a partir da primeira metade do século XX.

\section{Conclusão}

Para uma revisão minimamente aceitável e honesta da história literária do Amapá, é preciso estar atento a alguns sinais que esta pesquisa apresenta. Um deles é a vinculação entre os períodos políticos do espaço amapaense e sua respectiva produção literária. Neste caso, deve-se chamar atenção para a contribuição que as Letras amapaenses promovem quanto à interpretação do seu próprio tempo, não apenas do ponto de vista estético, mas também político, econômico e cultural, considerando o contexto amapaense enquanto Território Federal. Outro ponto importante a ser considerado no corpus desta pesquisa no Jornal Amapá, entre os anos 40 e 60 do século XX, é a presença marcante de escritores que se tornaram funcionários públicos no Amapá, o que, de alguma maneira, interferiu na linha ideológica da produção literária de alguns escritores daquele período.

Vale a pena investigar os limites da expressão artística no Território Federal do Amapá, levando em conta que alguns escritores desse período exerceram cargos importantes na política e no jornalismo amapaense. Por outro lado, emerge a discussão sobre o poder estético da literatura, mesmo num contexto preparatório para a ditadura militar no país (anos pré-1968), ou mesmo no segundo governo de Getúlio Vargas (anos 1940), quem determina o primeiro governador do Território Federal do Amapá, o militar Janari Gentil Nunes. Enfim, dentro desse contexto, investir no debate a partir das relações entre estética (literatura) e política parece ser um caminho viável para uma interpretação sobre a história literária do Amapá.

\section{Referências}

ACHUGAR Hugo. Planetas sem boca: escritos efêmeros sobre arte, cultura e literatura. Trad. Lyslei Nascimento. Belo Horizonte: UFMG, 2006.

BOBBIO, Norberto. O tempo da memória. Trad. Daniela Versiani. Rio de Janeiro: Campus, 1997.

BOURDIEU, Pierre. O poder simbólico. Trad. Fernando Tomaz. Rio de Janeiro: Bertrand Brasil, 2006.

DELGADO, Lucilia de A. Neves. História oral: memória, tempo, identidades. Belo Horizonte: Autêntica, 2010.

GIDDENS, Anthony. As consequências da Modernidade. Trad. Raul Fiker. São Paulo: Editora UNESP, 1991.

JORNAL AMAPÁ, Macapá. Edições dos anos de 1945 a 1968.

LAZARO, João (Ed.). Porta-retrato: Macapá/Amapá de outrora. https://porta-retrato-

Ainda como forma de protesto, mais tarde outros versos foram acrescentados: “A Avenida Getúlio Vargas/ Tá ficando que é um primô/ Tem hospital, tem escola/ Pros filho dos trabalhado/ Mas as casa foram feita/ Pra só mora os dotô". 
ap.blogspot.com.br/ (Blog).

MOREL, Marcos. Os primeiros passos da palavra imprensa. In: MARTINS, Ana

Luiza; LUCA, Tania Regina de (orgs.). História da imprensa no Brasil. São Paulo: Contexto, 2011.

NORA, Pierre. Entre memória e história: a problemática dos lugares. Trad. Yara Aun Khoury. São Paulo: Projeto História, 1993.

ORLANDI, Eni (org.). Discurso Fundador: a formação do país e a construção da identidade nacional. Campinas: Pontes, 1993.

VESENTINI, C. Na teia do fato. São Paulo: Brasiliense, 1997. 